\title{
Effects of intranasal administration with Bacillus subtilis on immune cells in the nasal mucosa and tonsils of piglets
}

\author{
YUNHAN YANG, YUCHAO JING, JINGJING YANG and QIAN YANG \\ MOE Joint International Research Laboratory of Animal Health and Food Safety, College of Veterinary Medicine, \\ Nanjing Agricultural University, Nanjing, Jiangsu 210095, P.R. China
}

Received August 17, 2017; Accepted December 15, 2017

DOI: $10.3892 /$ etm.2018.6093

\begin{abstract}
The nasal mucosa is the body's first barrier against pathogens entering through the respiratory tract. The respiratory immune system of pigs has more similarities with humans than the mouse respiratory system does, and so was selected as the animal model in the present study. To evaluate the effects of Bacillus subtilis as a potential probiotic to stimulate local immune responses, piglets were intranasally administered with Dylight 488-labeled B. subtilis (WB800-green fluorescent protein). The results revealed that $B$. subtilis was able to reach the lamina propria of the nasal mucosa, nasopharyngeal tonsils and soft palate tonsils. Piglets were subsequently administered intranasally with B. subtilis (WB800) at 3, 12 and 28 days. The results revealed that, following administration with $B$. subtilis, the number of dendritic cells, immunoglobulin $\mathrm{A}^{+} \mathrm{B}$ cells and $\mathrm{T}$ cells in the nasal mucosa and tonsils significantly increased $(\mathrm{P}<0.05)$. No obvious differences were observed in the morphological structure following $B$. subtilis administration. There were no statistical differences were observed in the expression of interleukin (IL)-1 $\beta$, tumor necrosis factor- $\alpha$ and IL- 8 mRNA between the $B$. subtilis treated group and the control group in the nasal mucosa, nasopharyngeal tonsil or soft palate tonsil. Toll-like receptor (TLR)-2 and TLR-9 mRNA expression in the tonsils was significantly increased following $B$. subtilis administration compared with the control group $(\mathrm{P}<0.05)$. The results demonstrate that $B$. subtilis administration increases the number of immune cells in the nasal mucosa and tonsils of piglets and stimulates nasal mucosal and tonsillar immunity. The present study lays the foundation for further study into the intranasal administration of B. subtilis in humans to enhance the immunity of human nasal mucosa to respiratory diseases.
\end{abstract}

Correspondence to: Professor Qian Yang, MOE Joint International Research Laboratory of Animal Health and Food Safety, College of Veterinary Medicine, Nanjing Agricultural University, 1 Weigang Road, Nanjing, Jiangsu 210095, P.R. China

E-mail: zxbyq@njau.edu.cn

Key words: piglets, intranasal administration, nasal mucosa, tonsil, Bacillus subtilis, immune cells

\section{Introduction}

Infectious respiratory diseases, including mycoplasma pneumonia and influenza, present a serious threat to public health $(1,2)$. The nasal mucosa is the primary invasion site for a number of pathogenic microorganisms and nasal immunization has the potential to increase mucosal immunity (3). The anatomy of the porcine respiratory system is similar to that of humans (more so than mice) and is considered to be a good animal model $(4,5)$. The tonsils are located near the nasal cavity, which is understood to serve the same role as the Waldeyer's ring in humans (6). Waldeyer's ring is located at the entrance to the digestive and respiratory tracts where it acts as a key component in the mucosal-associated lymphoid system (7). B and T cells are located within the nasal-associated lymphoid tissue and tonsils with antigen-presenting cells (APCs), including dendritic cells (DCs), interspersed among them $(8,9)$. The nasal mucosa and tonsils are considered to be a potential target for nasal vaccines as they serve an important role in antigen recognition and immune activation following intranasal administration, which is similar to gut-associated lymphoid tissue in the gastrointestinal tract $(10,11)$.

There are high numbers of DCs distributed under the nasal epithelium and, as the most ubiquitous professional APCs in the nasal mucosa and tonsils, they serve an important role in immune surveillance $(12,13)$. DCs are able to present antigens and activate $\mathrm{T}$ cell responses $(14,15)$.

Probiotics are defined as live microorganisms that confer a health benefit when administered at adequate concentrations (16). It has previously been suggested that probiotic bacteria interact with epithelial and immune cells from the innate immune system to reinforce the mucosal barrier (17). Probiotic bacteria may be sampled by DCs as whole cells or their antigenic fragments (17). Bacillus subtilis is a common probiotic with good biological safety that is able to effectively antagonize pathogenic bacteria (18). It has been reported that $B$. subtilis effectively enhances the innate immunity of the intestinal tract; however, whether B. subtilis is able to enhance the innate immunity of the nasal mucosa and tonsils remains unknown (19). The spores of B. subtilis have been successfully used for antigen delivery and they may also be used as a mucosal adjuvant for the H5N1 vaccine, in which they significantly enhance the effect of intranasal immunization $(20,21)$. The mechanism by which $B$. subtilis spores act as a potential 
immune adjuvant and whether this effect is associated with immune cells in the nasal mucosa and tonsils require further investigation.

In the present study, pigs were selected as the animal model to investigate the effects of $B$. subtilis on immune cells in the nasal mucosa and tonsils. Changes to the immune cells in the nasal mucosa and tonsils following intranasal administration with $B$. subtilis were observed. The results of the present study may be valuable for further study into an intranasal vaccines with $B$. subtilis as a mucosal adjuvant.

\section{Materials and methods}

Animals and reagents. A total of 6 (age, 1-month-old; weight, 13-16 kg) and 8 (age, 1-day-old; weight, 1.10-1.30 kg) male cross-bred Duroc/Landrace/Yorkshire piglets were obtained from Jiangsu Huai'an Pig Farm (Huai'an, China). A total of 2 cross-bred Landrace/Yorkshire sows (age, 1 year and 6 months; weight, 140-145 kg; Jiangsu Huai'an Pig Farm) were used to nurse the piglets. The pigs and piglets were housed in Jiangsu Huai'an Pig Farm with a constant humidity (60\%) and temperature $\left(26^{\circ} \mathrm{C}\right)$ at $12 \mathrm{~h} \mathrm{light/dark}$ cycle with free access to water and food. B. subtilis WB800 was obtained from the College of Plant Protection Nanjing Agricultural University (Nanjing, China).

Intranasal administration. A total of 6 1-month-old male piglets were randomly equally divided into two groups $(n=3)$ as follows: The control group was intranasally administrated with PBS (500 $\mu 1 /$ nostril) and the $B$. subtilis group was intranasally administrated with Dylight 488 (Life Technologies; Thermo Fisher Scientific, Inc., Waltham, MA, USA)-labeled B. subtilis WB800 spores $\left(10^{8} \mathrm{cfu} /\right.$ nostril). The procedure was repeated after $1 \mathrm{~h}$. Piglets were euthanized by intravenous injection of sodium pentobarbital $(100 \mathrm{mg} / \mathrm{kg}) 2 \mathrm{~h}$ later as previously described (22). All procedures were approved by the Institutional Animal Care and Use Committee of Nanjing Agricultural University (Nanjing, China) and followed the National Institutes of Health guidelines for the performance of animal experiments. Following sacrifice, the pigs were decapitated, the lower jaw and skin were removed and the muscles around the nasal cavity were removed. The nasal cavities, nasopharyngeal tonsils and soft palate tonsils were removed, fixed in $4 \%$ paraformaldehyde at room temperature for $6 \mathrm{~h}$, embedded in optimal cutting temperature compound (Sakura Finetek USA, Inc., Torrance, CA, USA) and cut into $8-\mu \mathrm{m}$-thick sections for immunofluorescence staining.

A total of 81 -day-old male piglets were bred in a pathogen free environment with the aforementioned conditions and randomly divided into two groups $(n=4)$ : The control group and the $B$. subtilis group. While the piglets were suckling, sows had free access to water and feed (containing no antibiotics). No pigs succumbed during the experiment. The $B$. subtilis group was intranasally administrated with $200 \mu \mathrm{l} /$ nostril B. subtilis WB800 $\left(10^{10} \mathrm{cfu} / \mathrm{ml}\right)$ on day 3, $500 \mu \mathrm{l} /$ nostril on day 12 and $1 \mathrm{ml} /$ nostril on day 21; these doses were selected from previous studies (22-26). The control group was treated with the same volumes of PBS. On day 28 the piglets were euthanized by intravenous injection of sodium pentobarbital. The nasal cavities, nasopharyngeal tonsils and soft palate tonsils were extracted and fixed in Bouin's fluid (Nanjing SenBeiJia Biological Technology Co., Ltd., Nanjing, China) for $48 \mathrm{~h}$ at $20-25^{\circ} \mathrm{C}$ for histological analysis, or stored at $-80^{\circ} \mathrm{C}$ for the detection of interleukin (IL)-1 $\beta$, tumor necrosis factor (TNF)- $\alpha$, IL-8, IL-6, porcine $\beta$-defensin 2 (pBD-2), toll-like receptor (TLR)-2, TLR-9 mRNA using reverse transcription-quantitative polymerase chain reaction (RT-qPCR). The nasal cavities were subsequently decalcified by dipping them in formic acid decalcifying solution (Nanjing SenBeiJia Biological Technology, Co., Ltd.) for 1 week. The tissues were embedded in paraffin, cut into $5-\mu \mathrm{m}$-thick sections, dewaxed in xylene, rehydrated in a graded series of ethanol $(100,90$, 80 and $70 \%$, each for $1 \mathrm{~min}$ ) and washed in PBS for immunohistochemistry, immunofluorescence, and hematoxylin and eosin (H\&E) staining. The sections were immersed in hematoxylin for $30 \mathrm{sec}$, PBS for $5 \mathrm{~min}$ and eosin for $5 \mathrm{sec}$. The sections were dehydrated through increasing concentrations of ethanol (70, 80, 90 and 100\%, each for $1 \mathrm{~min})$ and xylene. All processes are performed at room temperature.

Immunohistochemistry. The paraffin embedded sections were dewaxed in xylene and rehydrated in a graded series of ethanol (100, 90, 80 and $70 \%$, each for $1 \mathrm{~min})$. Sections were subsequently poached in a citrate buffer $(\mathrm{pH} 6)$ at $90-95^{\circ} \mathrm{C}$ for $15 \mathrm{~min}$ to retrieve antigens. The sections were treated with $0.3 \%$ hydrogen peroxide at room temperature for $15 \mathrm{~min}$ to quench endogenous peroxidase. The sections were blocked with $5 \%$ normal goat serum, $5 \%$ bovine serum albumin (BSA) and 5\% normal rabbit serum (all Boster Biological Technology, Pleasanton, CA, USA) for $30 \mathrm{~min}$ at room temperature. The sections were subsequently incubated with primary antibodies 1-4 listed in Table I for $12 \mathrm{~h}$ at $4^{\circ} \mathrm{C}$. Biotinylated secondary antibodies 1-4 listed in Table I were added to the sections for $1 \mathrm{~h}$ at room temperature. Positive cells were visualized by treatment with diaminobenzidine (DAB) for $60 \mathrm{~min}$ at room temperature, the sections were then sealed with neutral balata. The negative control was treated in the same way except the primary antibodies were omitted. The sections were visualized using a light microscope (Olympus CX23; Olympus Corporation, Tokyo, Japan) at a magnification of x400. A total of 15 fields of each tissue from each piglet were assessed for the statistical analysis.

Immunofluorescence and confocal microscopy. The frozen sections were incubated with 5\% BSA for $20 \mathrm{~min}$ at room temperature and subsequently incubated with $\mathrm{PE}$-conjugated goat anti-pig CD11b primary antibodies (Table I) at $4^{\circ} \mathrm{C}$ for $12 \mathrm{~h}$. The sections were washed in PBS and incubated with AlexaFluor 594-conjugated donkey anti-goat immunoglobulin G ( $\operatorname{IgG}) 2 \mathrm{~b}$ secondary antibodies at room temperature for $1 \mathrm{~h}$ (Table I). The sections were subsequently stained with DAPI solution (Invitrogen; Thermo Fisher Scientific, Inc.) at room temperature for $5 \mathrm{~min}$. The negative control was treated in the same way except the primary antibodies were omitted. The sections were visualized using a Zeiss LSM710 confocal microscope (Zeiss AG, Oberkochen, Germany) at a magnification of x1,000.

The paraffin embedded sections were rinsed and subjected to antigen retrieval as described above. The serum incubation and antibody incubations were the same as for the frozen sections described above. The primary antibodies used 


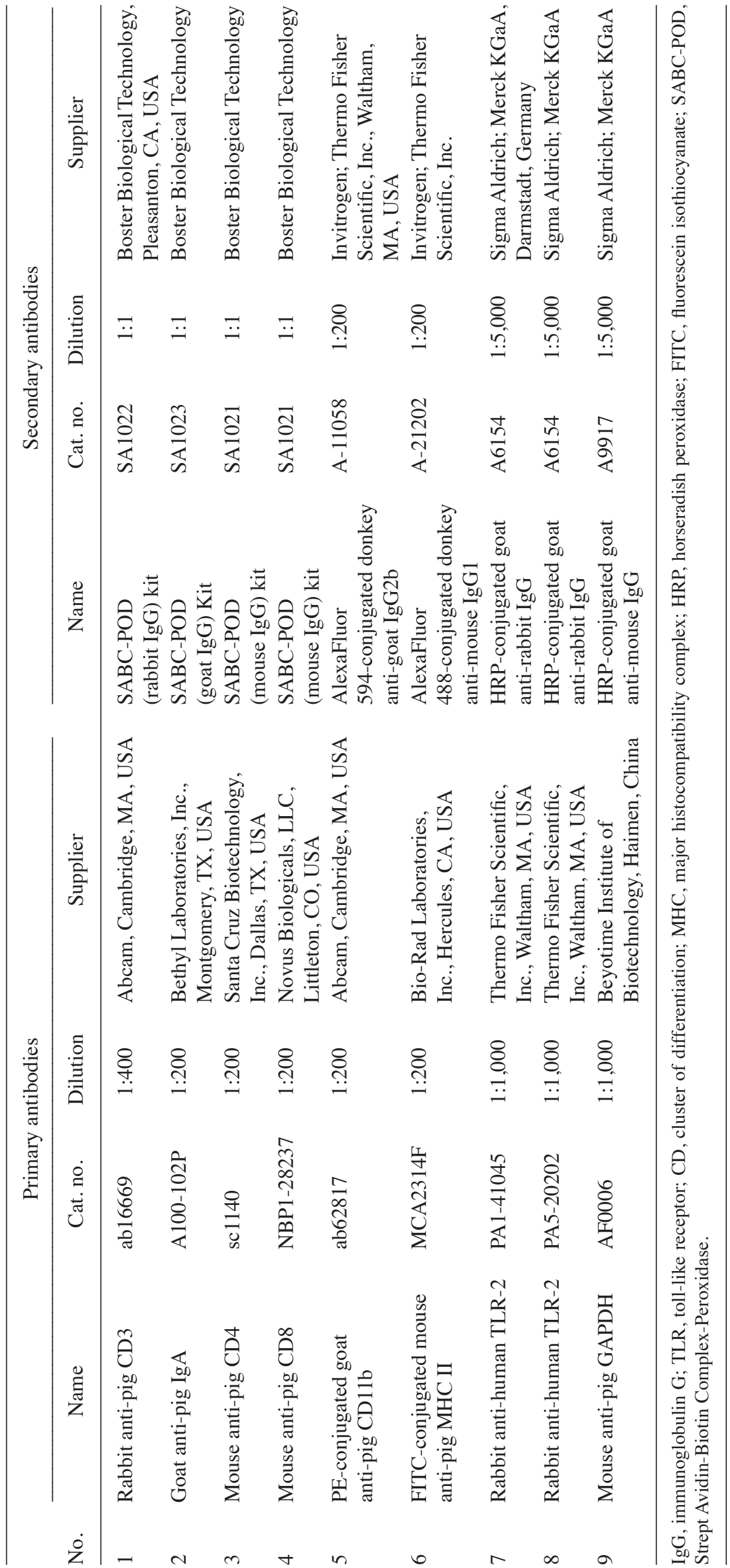


Table II. Oligonucleotide polymerase chain reaction primers.

\begin{tabular}{|c|c|c|c|}
\hline Gene & GenBank accession number & Primers sequence $\left(5^{\prime}-3^{\prime}\right)$ & Orientation \\
\hline \multirow[t]{2}{*}{ TNF- $\alpha$} & X57321.1 & CACCACGCTCTTCTGCCTACTGC & Forward \\
\hline & & TCGGCTTTGACATTGGCTACAA & Reverse \\
\hline \multirow[t]{2}{*}{ IL-8 } & NM213867 & TAGGACCAGAGCCAGGAAGA & Forward \\
\hline & & GAACTGCAGCCTCACAGAGA & Reverse \\
\hline \multirow[t]{2}{*}{$\mathrm{IL}-1 \beta$} & M86725.1 & AAGTGATGGCTAACTACGGTGAC & Forward \\
\hline & & ATCTGCCTGATGCTCTTGTTCC & Reverse \\
\hline \multirow[t]{2}{*}{ IL-6 } & M86722.1 & TGGATAAGCTGCAGTCACAG & Forward \\
\hline & & ATTATCCGAATGGCCCTCAG & Reverse \\
\hline \multirow[t]{2}{*}{ pBD-2 } & AY506573.1 & ACCTGCTTACGGGTCTTG & Forward \\
\hline & & CTCTGCTGTGGCTTCTGG & Reverse \\
\hline \multirow[t]{2}{*}{ TLR-2 } & AB072190 & ACATGAAGATGATGTGGGCC & Forward \\
\hline & & TAGGAGTCCTGCTCACTGTA & Reverse \\
\hline \multirow[t]{2}{*}{ TLR-9 } & AB071394 & GTGGAACTGTTTTGGCATC & Forward \\
\hline & & CACAGCACTCTGAGCTTTGT & Reverse \\
\hline \multirow[t]{2}{*}{$\beta$-actin } & U07786.1 & CATCACCATCGGCAACGA & Forward \\
\hline & & GCGTAGAGGTCCTTCCTGATGT & Reverse \\
\hline
\end{tabular}

TNF, tumor necrosis factor; IL, interleukin; TLR, toll-like receptor; $\mathrm{pBD}$, porcine $\beta$-defensin 2.

were PE-conjugated goat anti-pig CD11b and fluorescein isothiocyanate-conjugated mouse anti-pig major histocompatibility complex (MHC)II antibodies (Table I). The fluorescent secondary antibodies used were AlexaFluor 594-conjugated donkey anti-goat IgG2b and AlexaFluor 488-conjugated donkey anti-mouse IgG1 (Table I). A total of 15 different fields of each tissue type were assessed from each piglet for statistical analysis by using Image Pro Plus software (version 6.0; Media Cybernetics, Inc., Rockville, MD, USA).

$R N A$ isolation and RT-qPCR. Total RNA was extracted from mucosa segments using a TRIzol ${ }^{\mathrm{TM}}$ Plus RNA Purification kit (Thermo Fisher Scientific, Inc.). Total RNA (2 mg) reverse transcribed using PrimeScript ${ }^{\mathrm{TM}}$ RT-PCR kit (Takara Biotechnology Co., Ltd., Dalian, China) according to the manufacturer's protocol. Reverse transcription was performed at $37^{\circ} \mathrm{C}$ for $50 \mathrm{~min}$ and then at $70^{\circ} \mathrm{C}$ for $15 \mathrm{~min}$. A total of $2 \mu 1$ diluted cDNA (vol/:vol, 1:20) was used for RT-qPCR analysis, which was performed with an ABI 7500 PCR system (Life Technologies; Thermo Fisher Scientific, Inc.) using SYBR-Green qPCR Master Mix (Takara Biotechnology Co., Ltd., Dalian, China) according to the manufacturer's protocol. The thermocycling protocol was $95^{\circ} \mathrm{C}$ for $30 \mathrm{sec}$, followed by 40 cycles at $95^{\circ} \mathrm{C}$ for $5 \mathrm{sec}$ and $60^{\circ} \mathrm{C}$ for $31 \mathrm{sec}$. The data was normalized to the $\beta$-actin housekeeping gene to account for repeated measures. The specific primers used for PCR are listed in Table II. The porcine TNF- $\alpha$, IL- 8 , IL- $1 \beta$, IL-6, pBD-2, TLR-2 and TLR-9 primers were taken from Deng et al (27) and Khoufache et al (28). PCR products were analyzed using a melting curve and the results (fold change) were calculated using the $2^{-\Delta \Delta \mathrm{Cq}}$ method (29).

ELISA and western blot analysis. Tissue samples (50 mg) were homogenized in PBS using a Brinkman homogenizer and subjected to three freeze-thaw cycles $\left(-20^{\circ} \mathrm{C}\right.$ and $\left.37^{\circ} \mathrm{C}\right)$. The homogenates were subsequently centrifuged for $5 \mathrm{~min}$ at $5,000 \mathrm{x} \mathrm{g}$ at $4^{\circ} \mathrm{C}$. Levels of IL- $1 \beta$, IL- 8 and TNF- $\alpha$ proteins in the supernatant were analyzed using IL-1 $\beta$ (cat. no. 70-EK101B2), IL-8 (cat. no. 70-EK1082) and TNF- $\alpha$ (cat. no. 70-EK1822) ELISA kits [all Hangzhou MultiSciences (Lianke) Biotech, Co, Ltd., Hangzhou, China] according to the manufacturer's protocol. Each sample was run in triplicate.

Tissue samples $(50 \mathrm{mg})$ were homogenized in $500 \mu \mathrm{l}$ radioimmunoprecipitation assay lysis buffer (Beyotime Institute of Biotechnology, Shanghai, China) with a Brinkman Homogenizer. Total protein was extracted using a Protein Extraction kit (Beyotime Institute of Biotechnology) and protein content was measured using a bicinchoninic acid assay according to the manufacturer's protocol (Bio-Rad Laboratories, Inc., Hercules, CA, USA). The homogenates were subsequently centrifuged for $15 \mathrm{~min}$ at $14,000 \mathrm{xg}$ at $4^{\circ} \mathrm{C}$. The supernatant was diluted in a 5:1 ratio with SDS-PAGE Sample Loading Buffer (5X; Beyotime Institute of Biotechnology) and heated to $98^{\circ} \mathrm{C}$ for $10 \mathrm{~min}$. Proteins ( $40 \mathrm{mg} /$ lane) were separated in an $8 \%$ gel via SDS-PAGE. The protein was then transferred onto a $0.45 \mu \mathrm{m}$-pore polyvinylidene difluoride membrane (Immun-Blot ${ }^{\circledR}$; Bio-Rad Laboratories, Inc., Hercules, CA, USA) at $100 \mathrm{~V}$ for $1 \mathrm{~h}$. The membranes were blocked with $7 \%$ skim milk in PBS with $0.1 \%$ Tween-20 at room temperature for $2 \mathrm{~h}$. The TLR-2 and TLR-9 proteins were detected using western blot analysis with rabbit anti-human TLR-2 and rabbit anti-human TLR-9 polyclonal antibodies (Table I) for $10 \mathrm{~h}$ at $4{ }^{\circ} \mathrm{C}$, followed by horseradish peroxidase-conjugated goat anti-rabbit $\mathrm{IgG}$ secondary antibodies (Table I) for $1 \mathrm{~h}$ at room temperature. The signals were detected using Supersignal West Pico kit (Thermo Fisher Scientific, Inc.) and subjected to an ImageQuant LAS-4000 imaging system (GE Healthcare Bio-Sciences, Pittsburgh, PA, USA). The intensity of the bands in terms of 


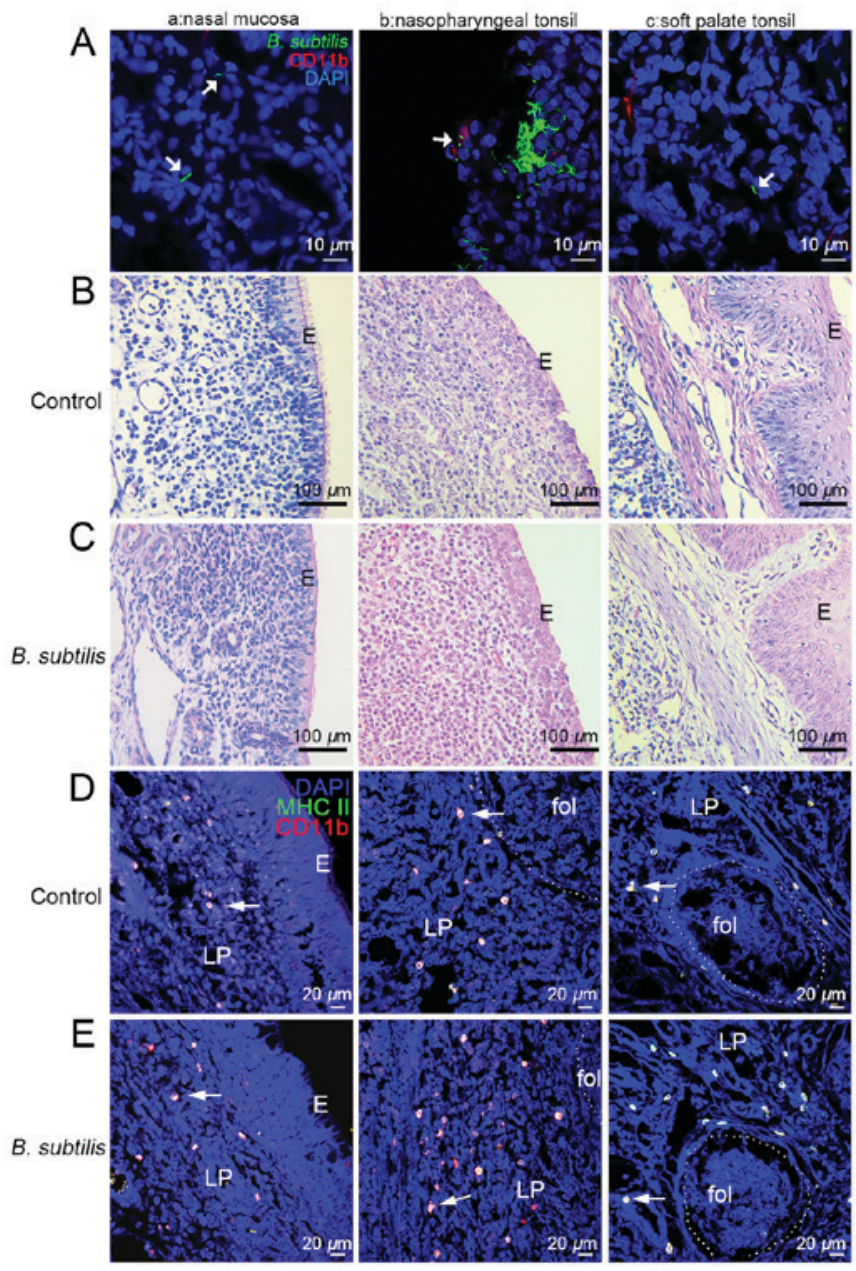

Figure 1. Effects of intranasal administration of B. subtilis on DCs in the nasal mucosa, nasopharyngeal tonsil and soft palate tonsils of piglets. (A) Immunofluorescent staining was performed to detect the prescence of Dylight 488-labeled B. subtilis (green) in the (A-a) lamina propria of nasal mucosa, (A-b) nasopharyngeal tonsil and (A-c) soft palate tonsil. CD11b ${ }^{+}$DCs were labelled as red and DAPI was labelled as blue. ( $n=3$ /group). Hematoxylin and eosin staining was performed on (B) control samples and (C) B. subtilis samples in the (B-a and C-a) nasal mucosa, (B-b and C-b) nasopharyngeal tonsil and (B-c and C-c) soft palate tonsil. Immunofluorescent staining was performed on (D) control samples and (E) B. subtilis samples. CD11b ${ }^{+}$(red) and $\mathrm{MHC} \mathrm{II}^{+}$(green) DCs (arrows) were detected in the (D-a and E-a) nasal mucosa, (D-b and E-b) nasopharyngeal tonsil, (D-c and E-c) and soft palate tonsil. CD11b ${ }^{+} \mathrm{MHC} \mathrm{II}^{+}$DCs were labelled as orange/yellow and DAPI was labelled as blue ( $n=4 /$ group). E, epithelium; LP, lamina propria; fol, lymphoid follicle; DCs, dendritic cells; CD, cluster of differentiaion.

density was measured by Image Pro Plus version 6.0 (Media Cybernetics, Inc.) and normalized against GAPDH expression. Three independent experiments and appropriate gel exposures yielded very similar results for each treatment modality.

Statistical analysis. Measurements and cell counts were performed using Image ProPlus version 6.0(Media Cybernetics, Inc.). Results are expressed as the mean \pm standard error of the mean. One-way analysis of variance, followed by Duncan's test, was employed to determine statistical differences among multiple groups and t-test was employed to determine the same between two groups. Histological scores were analyzed by the Mann-Whitney $\mathrm{U}$ test. $\mathrm{P}<0.05$ indicated that the difference between groups was statistically significant.

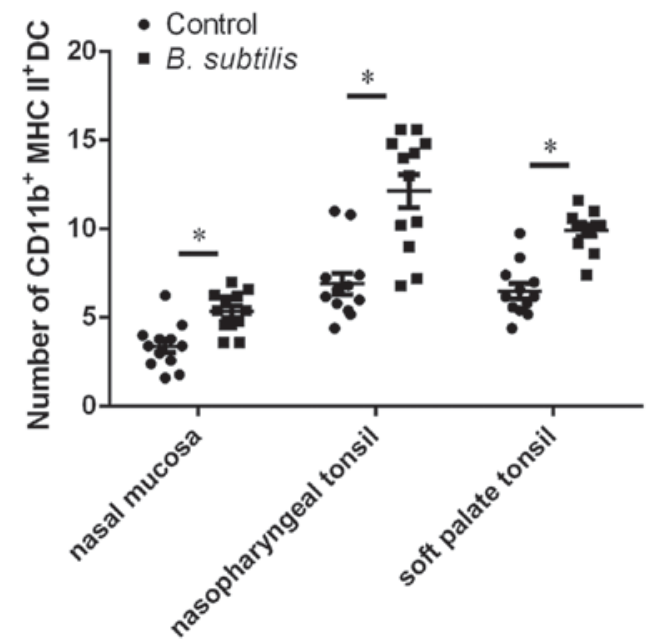

Figure 2. Point graph of the number of CD11b+MHC $\mathrm{II}^{+} \mathrm{DCs}$ in the nasal mucosa, nasopharyngeal tonsil and soft palate tonsil following intranasal administration of $B$. subtilis. The data are presented as the mean \pm standard error of the mean ( $n=4 /$ group). The error bars indicate the standard error. ${ }^{*} \mathrm{P}<0.05$. CD, cluster of differentiation; MHC, major histocompatibility complex; DC, dendritic cells.

\section{Results}

Analysis of B. subtilis location following intranasal administration. Dylight 488-labeled B. subtilis were observed in the lamina propria of the nasal mucosa, nasopharyngeal tonsils and soft palate tonsils, and the concentration of B. subtilis was markedly higher in the nasopharyngeal tonsil compared with the nasal mucosa or the soft palate tonsils (Fig. 1A). B. subtilis were also observed inside the CD11b ${ }^{+}$DCs (Fig. 1A-b). The morphological structure of the tissue did not appear to change and the epithelial integrity remained intact following intranasal administration with B. subtilis (Fig. 1B and $C$ ), which indicates that intranasal administration with $B$. subtilis did not cause pathological changes to the tissues.

Effect of B. subtilis on DCs in the nasal mucosa and tonsils. Immunofluorescent analysis via dual staining with antibodies specific to the DC markers to detected DCs. CD11b ${ }^{+}$cells were stained red, $\mathrm{MHC} \mathrm{II}^{+}$cells were stained green and double positive cells were stained bright yellow (arrows; Fig. 1D and E). There were several double positive cells and they were located in the lamina propria particularly around the lymphatic follicles (fol; dotted circles). The DCs were round or polygonal and distributed in the lamina propria particularly around the lymphatic follicles. CD $11 \mathrm{~b}^{+} \mathrm{MHC} \mathrm{II}^{+}$DCs were significantly increased in the nasal mucosa, nasopharyngeal tonsil and soft palate tonsil following administration with $B$. subtilis compared with the control ( $\mathrm{P}<0.05$; Fig. 2$)$.

Effect of B. subtilis on T cells in the nasal mucosa and tonsils. Immunohistochemical staining was performed on the paraffin embedded samples (Fig. 3). The results revealed that $\mathrm{CD}^{+}$, $\mathrm{CD}^{+}$and $\mathrm{CD}^{+} \mathrm{T}$ cells were widely distributed in the lamina propria of the nasal mucosa, soft palate tonsils and nasopharyngeal tonsils (Fig. 3A-F). The cells positively stained for $\mathrm{CD}^{+}, \mathrm{CD}^{+}$and $\mathrm{CD}^{+}$appeared brown. The number of $\mathrm{CD}^{+}$, $\mathrm{CD}^{+}$and $\mathrm{CD}^{+} \mathrm{T}$ cells in the nasal mucosa, nasopharyngeal 


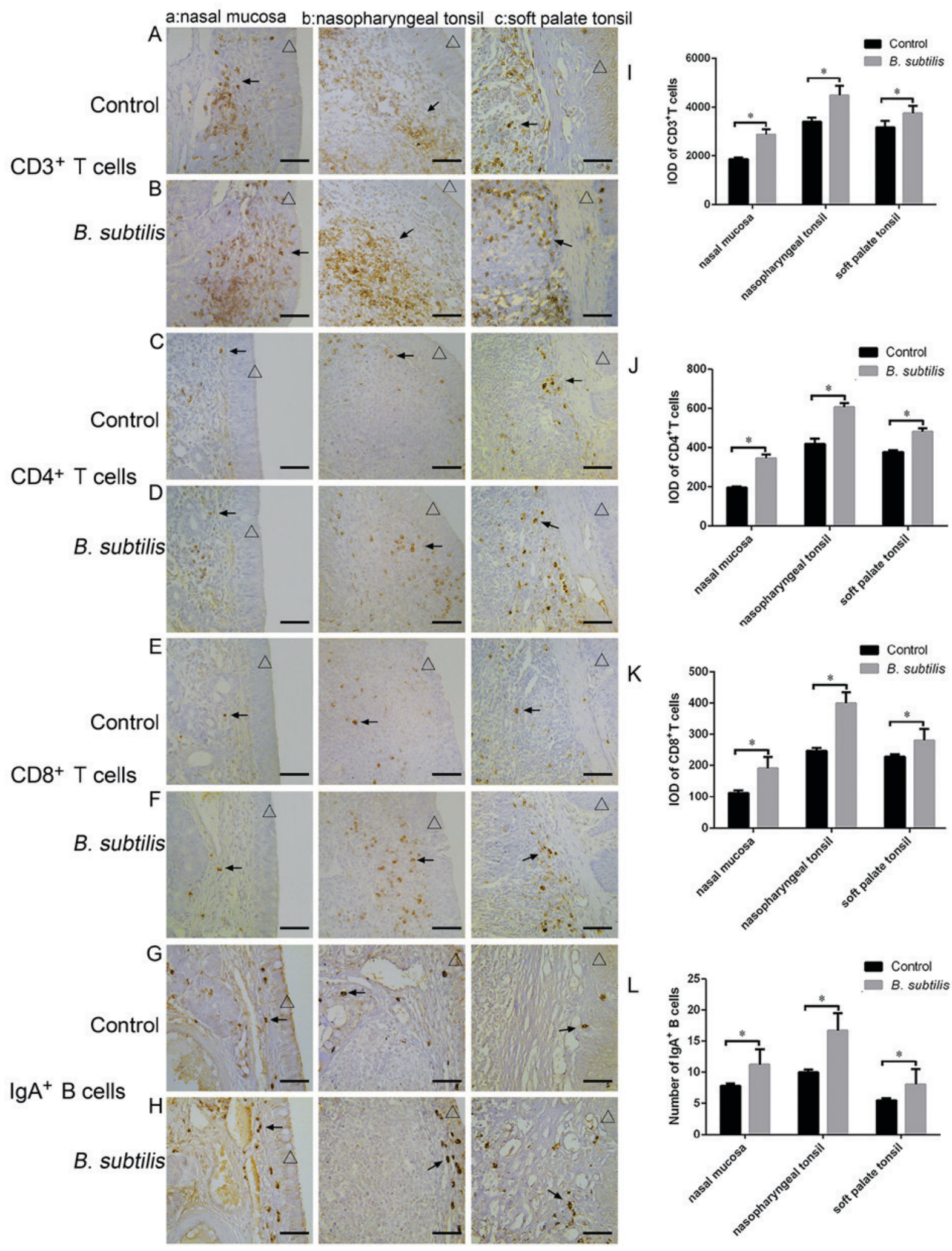

Figure 3. Effects of intranasal administration of $B$. subtilis on $\mathrm{CD}^{+}, \mathrm{CD} 4^{+}, \mathrm{CD} 8^{+} \mathrm{T}$ and $\operatorname{Ig} \mathrm{A}^{+} \mathrm{B}$ cells in the nasal mucosa, nasopharyngeal tonsil and soft palate tonsils of piglets. $\mathrm{CD} 3^{+} \mathrm{T}$ cells in in (A) control group and (B) B. subtilis group. CD4 ${ }^{+} \mathrm{T}$ cells in in (C) control group and (D) B. subtilis group. CD8 ${ }^{+} \mathrm{T}$ cells in in (E) control group and (F) B. subtilis group. Ig $\mathrm{A}^{+} \mathrm{B}$ cells in in $(\mathrm{G})$ control group and (H) B. subtilis group. (a) nasal mucosa, (b) nasopharyngeal tonsils and (c) soft palate tonsils. The triangle represents the epithelium. Scale bar, $100 \mu \mathrm{m}$. Bar graphs of the number of (I) $\mathrm{CD}^{+},(\mathrm{J}) \mathrm{CD}^{+}$and (K) $\mathrm{CD} 8^{+} \mathrm{T}$ cells and (L) $\mathrm{IgA} \mathrm{A}^{+} \mathrm{B}$ cells in in nasal mucosa, nasopharyngeal tonsils and soft palate tonsils. Triangles indicate the epithelium and arrows indicate positive cells. Data are presented as the mean \pm standard error of the mean ( $\mathrm{n}=4$ /group) and the error bars indicate the standard error. " $\mathrm{P}<0.05$. CD, cluster of differentiation; IgA, immunoglobulin A.

tonsil and soft palate tonsil increased significantly following the nasal administration of $B$. subtilis compared with the control ( $\mathrm{P}<0.05$; Fig. 3I-K).
Effect of B. subtilis on IgA+ $A^{+}$cells in the nasal mucosa and tonsils. Immunohistochemical staining revealed that the $\mathrm{IgA}^{+} \mathrm{B}$ cells (stained brown) were round or oval in shape and 


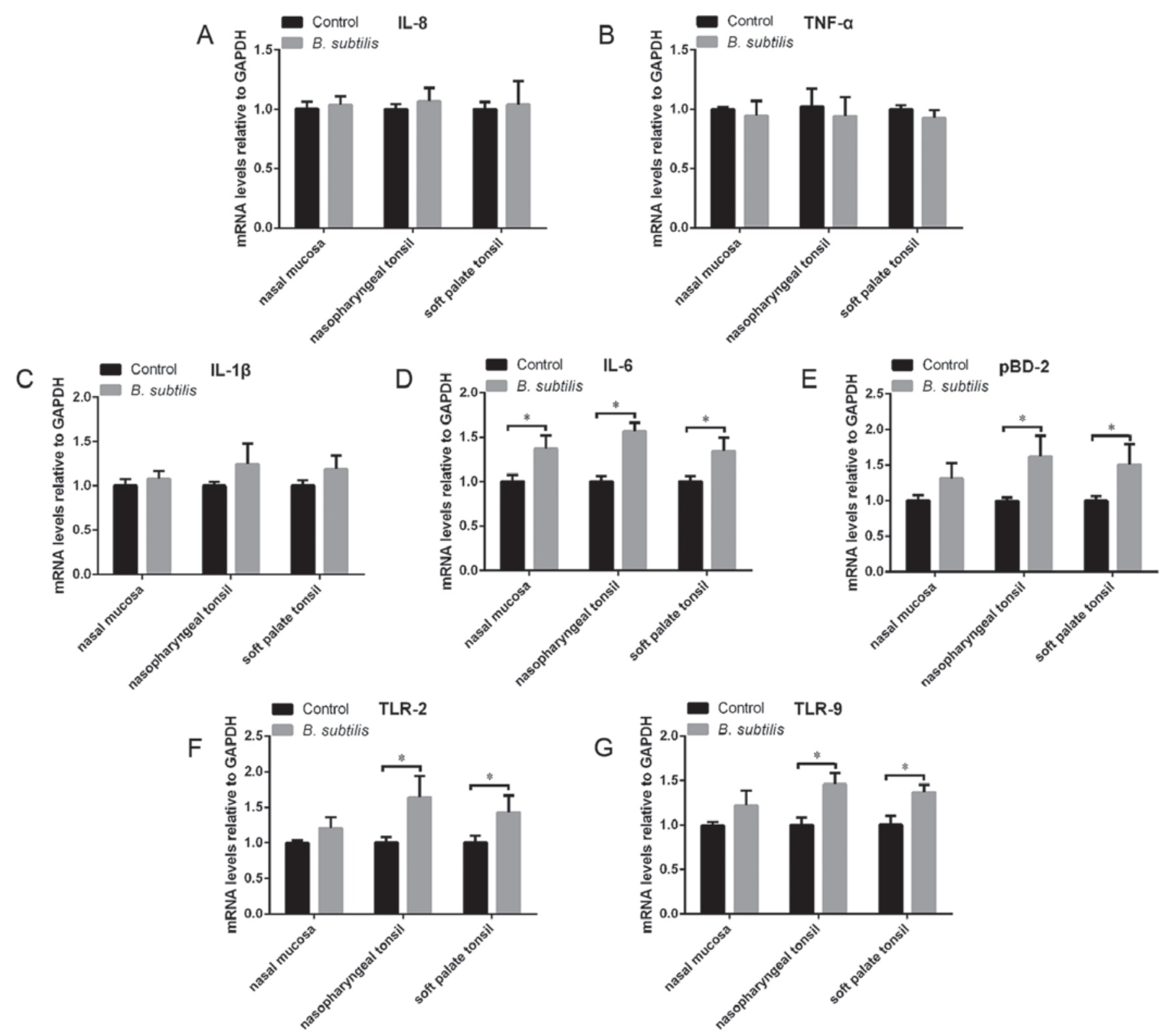

Figure 4. mRNA expression of (A) IL-8, (B) TNF- $\alpha$, (C) IL-1 $\beta$, (D) IL-6, (E) pBD-2, (F) TLR-2 and (G) TLR-9 in the nasal mucosa, nasopharyngeal tonsils and soft palate tonsils. Data are presented as the mean \pm standard error of the mean $(\mathrm{n}=4 / \mathrm{group})$ and the error bars indicate the standard error. " $\mathrm{P}<0.05$. IL, interleukin; TLR, toll-like receptor; TNF, tumor necrosis factor; pBD, porcine $\beta$-defensin 2.

primarily distributed in the lamina propria of the nasal mucosa, soft palate tonsils and nasopharyngeal tonsils (Fig. 3G-H). Following the intranasal administration of $B$. subtilis, the number of $\operatorname{IgA}^{+} \mathrm{B}$ cells was significantly increased in the nasal mucosa, nasopharyngeal tonsils and soft palate tonsils at 28 days post administration compared with the control $(\mathrm{P}<0.05$; Fig. 3L).

Expression of $I L-1 \beta, I L-6, I L-8, T N F-\alpha, p B D-2, T L R-2$ and $T L R-9 m R N A$. RT-qPCR was performed to determine the mRNA levels of IL-1 $\beta$, IL-6, IL-8, TNF- $\alpha$, pBD-2, TLR-2 and TLR-9 in the tissue samples (Fig. 4). The expression of IL-6 mRNA in the nasal cavities and tonsils increased significantly following the intranasal administration of $B$. subtilis compared with the control $(\mathrm{P}<0.05$; Fig. 4D). The expression of pBD-2, TLR-2 and TLR-9 mRNA also significantly increased following the administration of $B$. subtilis, but only in the tonsils $(\mathrm{P}<0.05$; Fig. $4 \mathrm{E}-\mathrm{G})$. These results indicate that the administration of $B$. subtilis stimulates nasal mucosal immunity. However, no statistical difference in mRNA expression was observed for IL- $1 \beta$, TNF- $\alpha$ and IL- 8 between the $B$. subtilis group and the control group in the nasal mucosa, nasopharyngeal tonsil or soft palate tonsil (Fig. 4A-C).

Protein expression of $I L-1 \beta, I L-8, T N F-\alpha, T L R-2, T L R-9$. No statistical differences in the protein expression of IL-1 $\beta$, TNF- $\alpha$ and IL- 8 were observed between the $B$. subtilis group and the control group in the nasal mucosa, nasopharyngeal tonsil or soft palate tonsil (Fig. 5A-C). The TLR-2 and TLR-9 protein levels in the nasal mucosa, nasopharyngeal tonsils and soft palate tonsils were significantly increased following intranasal administration of B. subtilis $(\mathrm{P}<0.05$; Fig. 5D-I). 

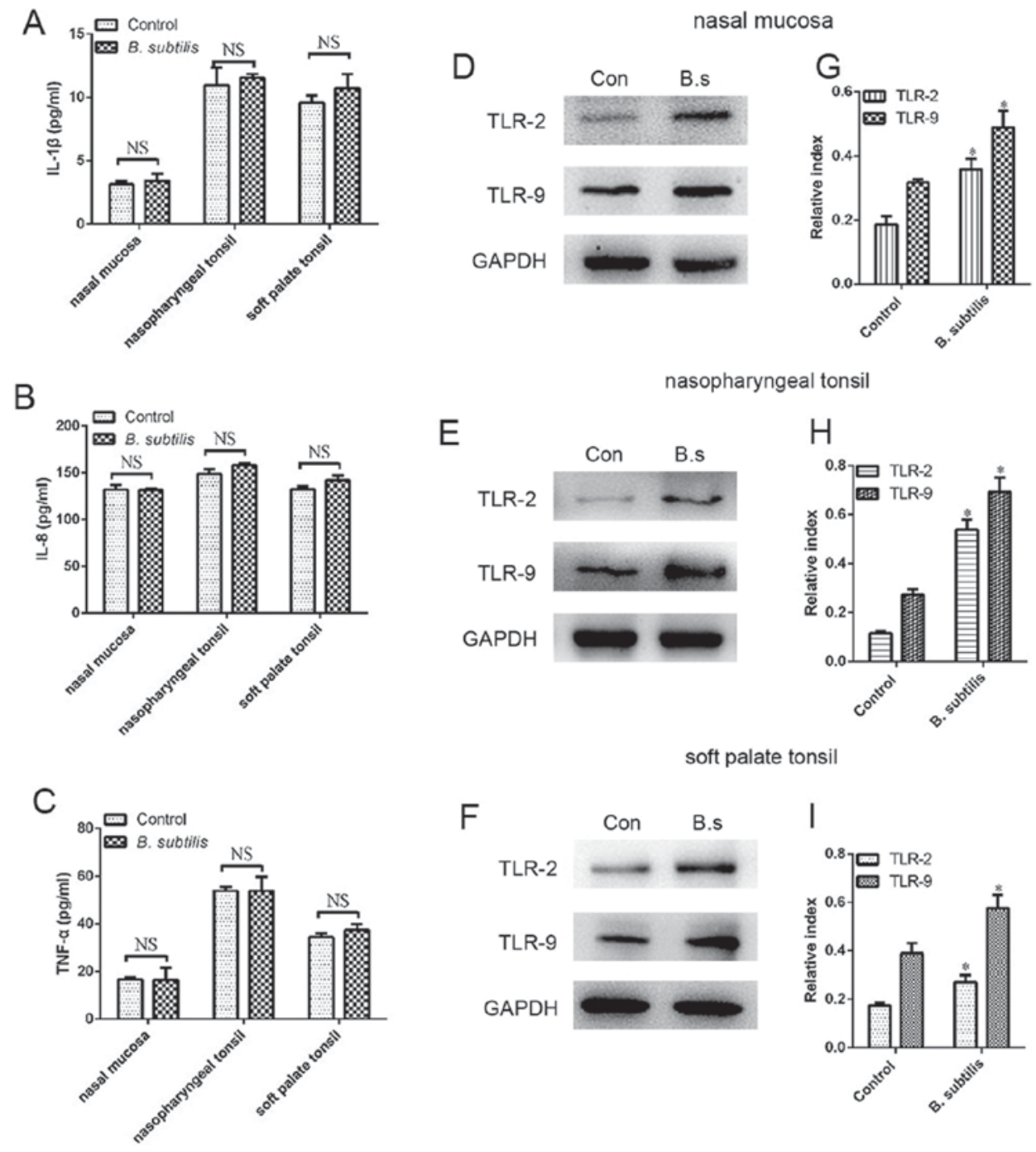

Figure 5. Protein expression of IL-1 $\beta$, IL-8, TNF- $\alpha$, TLR-2 and TLR-9 in the nasal mucosa, nasopharyngeal tonsils and soft palate tonsils. ELISA analysis of (A) IL-1 $\beta$, (B) IL-8 and (C) TNF- $\alpha$ in the nasal mucosa, nasopharyngeal tonsils and soft palate tonsils. Western blot analysis of TLR-2 and TLR-9 protein expression in the (D) nasal mucosa, (E) nasopharyngeal tonsils and (F) soft palate tonsils. TLR-2 and TLR-9 protein expression in the (G) nasal mucosa, (H) nasopharyngeal tonsils and (I) soft palate tonsils were normalized by comparison with GAPDH and the relative index was determined in comparison with the control. Values represent the mean \pm standard error of the mean ( $\mathrm{n}=4$ /group) and the error bars indicate the standard error. ${ }^{*} \mathrm{P}<0.05$. Con, the control group; B.s, the B. subtilis group; IL, interleukin; TLR, toll-like receptor; TNF, tumor necrosis factor.

\section{Discussion}

The innate immune system represents the first line of defense against pathogen invasion; the innate immunity of the respiratory tract in pigs has previously been studied due to its similarities with humans (30). Innate immunity functions through interactions between immune cells and TLRs, which are primarily expressed on APCs (31). The innate immune system promotes the activation of the adaptive immune system (32) and therefore serves an important role in the body's immune response. TLRs link the innate immune system with specific adaptive immunity (33). TLR-2 has a wide range of ligands, including lipoproteins and lipoteichoic acids from bacteria (34). TLR-9 is able to recognize bacterial DNA, which contains $\mathrm{CpG}$ motifs, and activate APCs and native B cells (35). In the present study, treatment with B. subtilis significantly increased TLR-2 and TLR-9 protein expression in the nasal mucosa, nasopharyngeal tonsils and soft palate tonsils. The results revealed that immunomodulation induced by B. subtilis WB800 primarily depends on extracellular macromolecules TLRs.

Secretory IgA, which is the main antibody for local mucosal immunity, is secreted by B cells (36). It may combine with antigens in the digestive and respiratory tracts and mediate virus neutralization in infected epithelial cells, or adhere to the mucosa to prevent pathogen translocation (37). DCs are the most ubiquitously distributed professional APCs (38) and are widely distributed throughout the secondary lymphoid organs (39). As the primary APCs in the nasal mucosa and tonsils, the protrusions of DCs may extend across the epithelium to uptake antigens and present them to T and B cells $(40,41)$. The maturation of DCs is a complex process during which they express surface molecules and cytokines, which are important for T-cell activation (42). It has previously been suggested that DCs were associated with the proliferation of $\mathrm{CD} 4^{+} \mathrm{T}$ cells, and that $\mathrm{DCs}$ may serve as APCs and upregulate $\mathrm{CD} 4^{+} \mathrm{T}$ cells in the nasal mucosa (40). The present study demonstrated that $B$. subtilis WB800 treatment significantly increased immune cells, indicating that it enhanced 
the local immunity of the piglets. A previous study has demonstrated that pBD-2 inhibits pathogens in vitro (27). T cells may produce cytokines that promote the maturation and differentiation of B lymphocytes into antibody producing cells $(43,44)$.

A previous study revealed that probiotics may upregulate the protein expression of pBD-2 in the saliva and intestines of piglets (45). In addition, it has been reported that the administration of probiotics increases the expression of IL- 6 in the nasal mucosa, nasopharyngeal tonsil and soft palate tonsil $(27,46,47)$. Based on this previous research, the authors of the present study hypothesized that the protein expression of pBD-2 and IL-6 would increase following the administration of $B$. subtilis. The focus of the present study was local immunity; however, the number of tissue samples was limited. To combat this, the expression of IL-1 $\beta$, IL-8, TNF- $\alpha$, TLR-2 and TLR-9 protein was measured in the nasal mucosa, nasopharyngeal tonsils and soft palate tonsils, all of which are key sites for local mucosal immunity. The present study revealed that IL- 6 mRNA was significantly increased in the nasal mucosa, nasopharyngeal tonsil and soft palate tonsil following intranasal administration of $B$. subtilis. This may be due to the regulative capability of $B$. subtilis in improving mucosal immune responses by inducing the production of IL-6. No statistical differences were observed in levels of pro-inflammatory factors TNF- $\alpha$, IL- $1 \beta$ and IL- 8 between the $B$. subtilis group and the control. These results indicate that the increase in immune cells and cytokines was not caused by inflammatory reactions. A previous study has reported that $B$. subtilis may effectively modulate the intestinal microbiota by enhancing the proliferation of beneficial bacteria and inhibiting potential pathogens, including Staphylococcus and Escherichia-Shigella, in the intestinal tract (48). A previous study reported that $B$. subtilis reduced Salmonella enteritidis attachment to the surfaces of intestinal epithelial cells (49). Based on this previous research, the authors of the present study hypothesized that $B$. subtilis had the ability to modulate the nasal microbiota and enhance the local mucosal immunity.

In conclusion, intranasal administration of $B$. subtilis increased the number of immune cells in the nasal mucosa, nasopharyngeal tonsils and soft palate tonsils, which enhanced the nasal mucosal and tonsillar immunity of piglets. The present study provides a basis for the further study of intranasal immunization with $B$. subtilis as a mucosal adjuvant. It also lays the foundation for the potential intranasal administration of B. subtilis in humans, which may enhance the immune response of human nasal mucosa against respiratory diseases.

\section{Acknowledgements}

Not applicable.

\section{Funding}

The present study was supported by the National Natural Science Foundation of China (grant no. 31172302) and a project funded by the Priority Academic Program Development of Jiangsu Higher Education Institutions.

\section{Availability of data and materials}

Not applicable.

\section{Authors' contributions}

YY and QY conceived and designed the study and wrote the paper. YY, YJ, and JY performed the experiments. YY, YJ, JY, and QY reviewed and edited the manuscript. All authors read and approved the manuscript.

\section{Ethics approval and consent to participate}

All procedures were approved by the Institutional Animal Care and Use Committee of Nanjing Agricultural University (Nanjing, China) and followed the National Institutes of Health guidelines for the performance of animal experiments.

\section{Consent for publication}

Not applicable.

\section{Competing interests}

The authors declare that they have no competing interests.

\section{References}

1. Meng Y, Yang Y, Lu W, Wang Y, Qian F, Wang X, Zhang Z and Wang W: The inhibition of Platycodin D on Mycoplasma pneumoniae proliferation and its effect on promoting cell growth after anti-Mycoplasma pneumoniae treatment. Front Cell Infect Microbiol 4: 192, 2015.

2. Kim TK, Bheda-Malge A, Lin Y, Sreekrishna K, Adams R, Robinson MK, Bascom CC, Tiesman JP, Isfort RJ and Gelinas R: A systems approach to understanding human rhinovirus and influenza virus infection. Virology 486: 146-157, 2015.

3. Persson J, Zhang Y, Olafsdottir TA, Thörn K, Cairns TM, Wegmann F, Sattentau QJ, Eisenberg RJ, Cohen GH and Harandi AM: Nasal immunization confers high avidity neutralizing antibody response and immunity to primary and recurrent genital herpes in guinea pigs. Front Immunol 7: 640, 2016.

4. Yang J, Dai L, Yu QH and Yang Q: Histological and anatomical structure of the nasal cavity of Bama minipigs. PLoS One 12: e0173902, 2017.

5. Amuguni H, Lee S, Kerstein K, Brown D, Belitsky B, Herrmann J, Keusch G, Sonenshein A and Tzipori S: Sublingual immunization with an engineered Bacillus subtilis strain expressing tetanus toxin fragment $\mathrm{C}$ induces systemic and mucosal immune responses in piglets. Microbes Infect 14: 447-456, 2012.

6. Hellings P, Jorissen M and Ceuppens JL: The Waldeyer's ring. Acta Otorhinolaryngol Belg 54: 237-241, 2000.

7. Casteleyn C, Breugelmans S, Simoens P and Van den Broeck W: The tonsils revisited: Review of the anatomical localization and histological characteristics of the tonsils of domestic and laboratory animals. Clin Dev Immunol 2011: 472460, 2011.

8. Cisney ED, Fernandez S, Hall SI, Krietz GA and Ulrich RG: Examining the role of nasopharyngeal-associated lymphoreticular tissue (NALT) in mouse responses to vaccines. J Vis Exp: 3960, 2012

9. Casteleyn C, Broos AM, Simoens P and Van den Broeck W: NALT (nasal cavity-associated lymphoid tissue) in the rabbit. Vet Immunol Immunopathol 133: 212-218, 2010.

10. Pabst R: Mucosal vaccination by the intranasal route. Nose-associated lymphoid tissue (NALT)-Structure, function and species differences. Vaccine 33: 4406-4413, 2015.

11. Brandtzaeg P and Pabst R: Let's go mucosal: Communication on slippery ground. Trends Immunol 25: 570-577, 2004.

12. Khaiboullina SF, Morzunov SP, Hall MR, De Meirleir KL, Rizvanov AA and Lombardi VC: Human dendritic cells transfected with a human papilloma virus-18 construct display decreased mobility and upregulated cytokine production. Int J Oncol 43: 1701-1709, 2013. 
13. Rate A, Bosco A, McKenna KL, Holt PG and Upham JW: Airway epithelial cells condition dendritic cells to express multiple immune surveillance genes. PLoS One 7: e44941, 2012.

14. Nakahara T, Moroi Y, Uchi H and Furue M: Differential role of MAPK signaling in human dendritic cell maturation and Th1/Th2 engagement. J. Dermatol Sci 42: 1-11, 2006.

15. Jamin A, Gorin S, Le Potier MF and Kuntz-Simon G: Characterization of conventional and plasmacytoid dendritic cells in swine secondary lymphoid organs and blood. Vet Immunol Immunopathol 114: 224-237, 2006.

16. Fijan S: Microorganisms with claimed probiotic properties: An overview of recent literature. Int J Environ Res Public Health 11: 4745-4767, 2014

17. Galdeano CM, de Moreno de LeBlanc A, Vinderola G, Bonet ME and Perdigón G: Proposed model: Mechanisms of immunomodulation induced by probiotic bacteria. Clin Vaccine Immunol 14: 485-492, 2007.

18. Toure Y, Ongena M, Jacques P, Guiro A and Thonart P: Role of lipopeptides produced by Bacillus subtilis GA1 in the reduction of grey mould disease caused by Botrytis cinerea on apple. J Appl Microbiol 96: 1151-1160, 2004.

19. Huang JM, La Ragione RM, Nunez A and Cutting SM: Immunostimulatory activity of Bacillus spores. FEMS Immunol Med Microbiol 53: 195-203, 2008.

20. Liang J, Fu J, Kang H, Lin J, Yu Q and Yang Q: Comparison of 3 kinds of Toll-like receptor ligands for inactivated avian $\mathrm{H} 5 \mathrm{~N} 1$ influenza virus intranasal immunization in chicken. Poult Sci 92: 2651-2660, 2013.

21. Song M, Hong HA, Huang JM, Colenutt C, Khang DD Nguyen TV, Park SM, Shim BS, Song HH, Cheon IS, et al: Killed Bacillus subtilis spores as a mucosal adjuvant for an $\mathrm{H} 5 \mathrm{~N} 1$ vaccine. Vaccine 30: 3266-3277, 2012.

22. Mou C, Zhu L, Yang J, Xu W, Cheng X and Yang Q: Immune responses induced by recombinant Bacillus subtilis expressing the hemagglutinin protein of H5N1 in chickens. Sci Rep 6: 38403, 2016.

23. Upadhaya SD, Shanmugam SK, Kang DK and Kim IH: Preliminary assessment on potentials of probiotic B. subtilis RX7 and B. methylotrophicus C14 strains as an immune modulator in Salmonella-challenged weaned pigs. Trop Anim Health Prod 49: 1065-1070, 2017.

24. Zhang W, Zhu YH, Zhou D, Wu Q, Song D, Dicksved J and Wang JF: Oral administration of a select mixture of Bacillus probiotics affects the gut microbiota and goblet cell function following Escherichia coli challenge in newly weaned pigs of genotype MUC4 that are supposed to be enterotoxigenic E. coli F4ab/ac receptor negative. Appl Environ Microbiol 83: pii: e02747-16, 2017.

25. Sheng QK, Zhou KF, Hu HM, Zhao HB, Zhang Y and Ying W: Effect of Bacillus subtilis natto on meat quality and skatole content in TOPIGS pigs. Asian-Australas J Anim Sci 29: 716-721, 2016.

26. Shi C, Zhang Y, Lu Z and Wang Y: Solid-state fermentation of corn-soybean meal mixed feed with Bacillus subtilis and Enterococcus faecium for degrading antinutritional factors and enhancing nutritional value. J Anim Sci Biotechnol 8: 50, 2017.

27. Deng J, Li Y,Zhang J and Yang Q: Co-administration of Bacillus subtilis RJGP16 and Lactobacillus salivarius B1 strongly enhances the intestinal mucosal immunity of piglets. Res Vet Sci 94: 62-68, 2013

28. Khoufache K, Cabaret O, Farrugia C, Rivollet D, Alliot A, Allaire E, Cordonnier C, Bretagne S and Botterel F: Primary in vitro culture of porcine tracheal epithelial cells in an air-liquid interface as a model to study airway epithelium and Aspergillus fumigatus interactions. Med Mycol 48: 1049-1055, 2010.

29. Livak KJ and Schmittgen TD: Analysis of relative gene expression data using real-time quantitative PCR and the 2(-Delta Delta C(T)) method. Methods 25: 402-408, 2001.

30. Loving CL, Osorio FA, Murtaugh MP and Zuckermann FA: Innate and adaptive immunity against porcine reproductive and respiratory syndrome virus. Vet Immunol Immunopathol 167 $1-14,2015$

31. Tu S, Zhong D, Xie W, Huang W, Jiang Y and Li Y: Role of toll-like receptor signaling in the pathogenesis of graft-versus-host diseases. Int J Mol Sci 17: pii: E1288, 2016.
32. Romo MR, Pérez-Martinez D and Castillo Ferrer C: Innate immunity in vertebrates: An overview. Immunology 148: 125-139, 2016

33. Zhang EJ and Lu MJ: Toll-like receptor (TLR)-mediated innate immune responses in the control of hepatitis B virus (HBV) infection. Med. Microbiol Immunol 204: 11-20, 2015.

34. Modlin RL: Mammalian toll-like receptors. Ann Allerg Asthma Immunol 88: 543-548, 2002.

35. Giordani L, Sanchez M, Libri I, Quaranta MG, Mattioli B and Viora M: IFN- $\alpha$ amplifies human naive B cell TLR-9-mediated activation and Ig production. J Leukocyte Biol 86: 261-271, 2009.

36. Luo Q, Cui HM, Peng X, Fang J, Zuo Z, Deng J, Liu J and Deng Y: Intestinal $\operatorname{Ig} \mathrm{A}^{+}$cell numbers as well as $\operatorname{IgA}, \operatorname{IgG}$, and $\operatorname{IgM}$ contents correlate with mucosal humoral immunity of broilers during supplementation with high fluorine in the diets. Biol Trace Elem Res 154: 62-72, 2013.

37. Wu B, Cui H, Peng X, Fang J, Zuo Z, Deng J and Huang J: Toxicological effects of nickel chloride on $\operatorname{Ig} \mathrm{A}^{+} \mathrm{B}$ cells and $\operatorname{sg} \mathrm{A}$, $\operatorname{IgA}, \operatorname{IgG}, \operatorname{IgM}$ in the intestinal mucosal immunity in broilers. Int J Environ Res Public Health 11: 8175-8192, 2014

38. Gao Q, Zhao S, Qin T, Yin Y, Yu Q and Yang Q: Effects of inactivated porcine epidemic diarrhea virus on porcine monocyte-derived dendritic cells and intestinal dendritic cells. Res Vet Sci 106: 149-158, 2016.

39. Durand M and Segura E: Dendritic cell subset purification from human tonsils and lymph nodes. Methods Mol Biol 1423: 89-99, 2016.

40. Fukuyama Y, Tokuhara D, Sekine S, Kataoka K, Markham JD, Irwin AR, Moon GH, Tokuhara Y, Fujihashi K, Davydova J, et al: Notch-ligand expression by NALT dendritic cells regulates mucosal Th1- and Th2-type responses. Biochem Biophys Res Commun 418: 6-11, 2012.

41. Qin T, Yin Y, Wang X, Liu H, Lin J, Yu Q and Yang Q: Whole inactivated avian Influenza H9N2 viruses induce nasal submucosal dendritic cells to sample luminal viruses via transepithelial dendrites and trigger subsequent DC maturation. Vaccine 33: 1382-1392, 2015.

42. Sundara Rajan S and Longhi MP: Dendritic cells and adipose tissue. Immunology 149: 353-361, 2016.

43. Lammers A, Wieland WH, Kruijt L, Jansma A, Straetemans T, Schots A, den Hartog G and Parmentier HK: Successive immunoglobulin and cytokine expression in the small intestine of juvenile chicken. Dev Comp Immunol 34: 1254-1262, 2010.

44. Moutsopoulos NM, Nares S, Nikitakis N, Rangel Z, Wen J, Munson P, Sauk J and Wahl SM: Tonsil epithelial factors may influence oropharyngeal human immunodeficiency virus transmission. Am J Pathol 171: 571-579, 2007.

45. Zhang J, Deng J, Li Y and Yang Q: The effect of Lactobacillus on the expression of porcine $\beta$-defensin- 2 in the digestive tract of piglets. Livestock Sci 138: 259-265, 2011.

46. Zhou D, Zhu YH, Zhang W, Wang ML, Fan WY, Song D, Yang GY, Jensen BB and Wang JF: Oral administration of a select mixture of Bacillus probiotics generates $\operatorname{Tr} 1$ cells in weaned F4ab/acR pigs challenged with an $\mathrm{F}^{+}{ }^{+}$ETEC/VTEC/EPEC strain. Vet Res 46: 95, 2015

47. Cilieborg MS, Thymann T, Siggers R, Boye M, Bering SB, Jensen BB and Sangild PT: The incidence of necrotizing enterocolitis is increased following probiotic administration to preterm pigs. J Nutr 141: 223-230, 2011

48. Li Y, Xu Q, Huang Z, Lv L, Liu X, Yin C, Yan H and Yuan J: Effect of Bacillus subtilis CGMCC 1.1086 on the growth performance and intestinal microbiota of broilers. J Appl Microbiol 120: 195-204, 2016.

49. Thirabunyanon M and Thongwittaya N: Protection activity of a novel probiotic strain of Bacillus subtilis against Salmonella Enteritidis infection. Res Vet Sci 93: 74-81, 2012.

This work is licensed under a Creative Commons Attribution-NonCommercial-NoDerivatives 4.0 International (CC BY-NC-ND 4.0) License. 